\title{
Integrating Authentic Research Into the Emory-Tibet Science Initiative
}

\author{
Robin Nusslock ${ }^{1 *}$, Nicole M. Gerardo ${ }^{2}$, Jennifer S. Mascaro ${ }^{3}$, Jacob Shreckengost ${ }^{4}$ and \\ Meena M. Balgopal ${ }^{5}$ \\ ${ }^{1}$ Department of Psychology and Institute for Policy Research, Northwestern University, Evanston, IL, United States, ${ }^{2}$ Department \\ of Biology, Emory University, Atlanta, GA, United States, ${ }^{3}$ Division of Preventive Medicine, Department of Family and Preventive \\ Medicine, Emory University School of Medicine, Atlanta, GA, United States, ${ }^{4}$ Craig H. Neilsen Foundation, Encino, CA, \\ United States, ${ }^{5}$ Department of Biology, Colorado State University, Fort Collins, CO, United States
}

OPEN ACCESS

Edited by:

José Castro-Sotomayor, California State University, Channel Islands, United States

Reviewed by:

Richard William Stoffle, University of Arizona, United States David Kimelman, University of Washington, United States

${ }^{*}$ Correspondence: Robin Nusslock nusslock@northwestern.edu

Specialty section: This article was submitted to Science and Environmental Communication,

a section of the journal Frontiers in Communication

Received: 31 August 2021 Accepted: 04 January 2022 Published: 02 February 2022

Citation: Nusslock R, Gerardo NM, Mascaro JS, Shreckengost $J$ and Balgopal MM (2022) Integrating Authentic Research Into the Emory-Tibet Science Initiative.

Front. Commun. 7:767547. doi: 10.3389/fcomm.2022.767547
We are at a historic point in which scientists and Tibetan monastics are working together to investigate ancient questions of mind and matter, and to serve the best interests of humanity. To facilitate this collaboration, His Holiness the Dalai Lama supported the development of the Emory University-Tibet Science Initiative (ETSI), which reflects the first major change in the Tibetan monastic curriculum in six centuries. Over the course of a 6year long curriculum, Tibetan monastics living in India have the opportunity to study science with experts in various disciplines. In 2019, ETSI graduated its first cohort of monastic students from a 6-year "implementation phase," and now has entered the "sustainability phase." A goal of the sustainability phase is to broaden the scope of ETSI and begin training monastics through research. The present paper provides an overview of a 3-year Research Training Program being developed for the sustainability phase. We first overview a pilot program that informed feasibility and potential structure for a broader Research Training Program at the monasteries and monastic universities in India. Next, we discuss the conceptual framework for the Research Training Program and four learning objectives that we hope to attain. We then discuss the specifics of the course design for the proposed 3-year research training curriculum, through which our goal is to transition from a more guided training experience to a less guided experience. Finally, we discuss challenges and opportunities that we expect to encounter in developing and implementing the program.

\footnotetext{
Keywords: research-development-innovation, education-active learning, buddhism, neuroscience, international and comparative education
}

\section{INTRODUCTION}

For many years, the Dalai Lama has engaged in a conversation with scientists to examine how academic science and the time-honored wisdom of Indo-Tibetan traditions can work together to best serve the interests of humanity. These conversations highlight important similarities in the investigative spirit between academic science and Buddhist thought. Both science and Buddhism are committed to an empirical investigation of reality. They also share a willingness to discard longheld positions if such investigations suggest that reality is different than existing models or theories (Ladyman, 2002; Dalai Lama, 2005). For example, although Buddhism is a religion with a body of scriptures and rituals, Buddhist scriptural authority, according to the Dalai Lama, cannot outweigh an understanding based on reasoned examination and experience (Dalai Lama, 2005; Jinpa, 2010). 
Despite their shared commitment to an empirical mindset, science and Buddhism frequently differ in their methods. Science typically takes a third-person perspective involving measurement, quantification, and verification through experiments (Popper, 1959). Buddhism, by contrast, highlights the importance of a first-person perspective and the direct observation of both inner and outer states, as well as reason and analysis (Wallace, 2003). Many scientists and Buddhist thinkers, including the Dalai Lama, believe that we are at a point in history where these two traditions can, and should, start working more closely together to help humanity meet its challenges (Davidson and Lutz, 2008; Eisen and Konchok, 2017). To facilitate this relationship, the Dalai Lama has been working with Emory University for over 20 years on initiatives to increase cross-talk between science and spirituality. As this collaboration progressed, it became evident that Tibetan monastics needed more specific training in academic science to fully participate in the dialogue (Sonam, 2019). The Emory-Tibet Science Initiative (ETSI) emerged from this insight (Eisen and Konchok, 2017).

ETSI is an historic educational project conceived and supported by the Dalai Lama, and formally launched in 2008 by Emory University in collaboration with the Library of Tibetan Works and Archives in India (Sonam, 2019). The goal of ETSI is to integrate academic science into the education of thousands of displaced Tibetan Buddhist monks and nuns living in India, reflecting the first major change in the monastic curriculum in six centuries. Supported by ETSI, Tibetan monasteries and monastic universities have hosted international science educators from dozens of universities for an annual science curriculum intensive for monks and nuns. Over the course of a 6-year long implementation phase covering philosophy of science, physics, neuroscience, and biology, monastics study science with experts in various disciplines. A goal of ETSI is to build a bridge between two complementary systems of knowledge by educating future scientific collaborators in the study of mind and body. In addition to helping provide Tibetan monastics new tools for understanding the world, the academic scientists and educators are encouraged to learn more about the Buddhist science of mind and what it can contribute to our understanding of consciousness and integrative approaches to health and well-being.

In 2019, ETSI graduated its first cohort of monastic students from the implementation phase-a total of 233 monastics from nine monastic academic institutions-who completed the 6-year science curriculum, and ETSI now has entered the "sustainability phase." At the time of the publication of this paper, approximately 60 monastic students have begun the sustainability phase. All of these students have completed at least four of the total 6 years of the ETSI implementation phase and have demonstrated a strong interest in continuing to learn more science both for their own knowledge and to become better teachers of future monastic ETSI students. One goal of the sustainability phase is to help Tibetan monastics develop an understanding of the conceptual and theoretical foundations of the scientific process by doing research. This new direction in ETSI opens up a number of exciting opportunities for Tibetan monastics and academic scientists.
First, it aligns with the body of literature that emphasizes the value of doing science in order to learn science (National Research Council, 2003; National Research Council, 2012). Second, it should provide monastics an opportunity to identify the similarities and differences in the empirical modes of investigation between science and Buddhism. Third, it will allow monastics to move from acquiring scientific knowledge to generating and using scientific knowledge to ask questions and solve problems (Balgopal et al., 2021). While teaching science in traditional classroom settings exposes students to facts and concepts, and guides them towards a better understanding of natural phenomena, science also includes the process of identifying patterns and testing hypotheses in order to gain novel insights (Russell, 2001). Numerous studies have demonstrated that engaging students in the process of doing science increases interest in science and helps students have a deeper understanding of the material (Furtak et al., 2012; Marshall et al., 2017; Labouta et al., 2018). For these reasons, the ETSI sustainability phase will help monastics design and execute research projects. In doing so, the ETSI research training program will facilitate the Dalai Lama's goal of generating collaborative relationships between scientists and monastics to investigate the mysteries of mind, emotion, and consciousness.

ETSI is in the early stages of developing and implementing what will be a 3-year Research Training Program for the sustainability phase. Here, we provide an overview of the conceptual foundations and planned structure of this training program.

\section{A RESEARCH TRAINING PILOT PROJECT}

To explore the challenges, opportunities, and feasibility of establishing a research program, ETSI facilitated a research training pilot program in conjunction with the inauguration of the Drepung Loseling Meditation and Science Center in India in 2017. The pilot program was designed for monastics to develop authentic research projects, building on both their own interests and on the training that they had received in the biological sciences through the ETSI curriculum. Four of us (Balgopal, Shreckengost, Mascaro, Gerardo) led the 8-day long workshop. We capitalized on the literature on Course-Based Undergraduate Research Experiences (CUREs) as a framework, which emphasizes context, discovery, iteration, ownership, communication, and presentation (Auchincloss et al., 2014; Staub et al., 2016). Because one of the goals of ETSI is to prepare some monastics to become science teachers, we modeled best pedagogical practices by limiting lectures and letting monastics explore topics through active participation. In this way, we demonstrated that inquiry-based teaching can support research inquiry. In both research and active learning, individuals ask questions, identify what background knowledge they have, what new knowledge they want, and how they can best generate the new knowledge. As a student, this may mean that one identifies what active learning approaches are effective for them. As a researcher, this may mean clearly articulating research goals and design before embarking on the study. 


\section{Example at Intersection of Ecology, Environmental Science, and Public Health: Malaria Transmission by Mosquitoes}

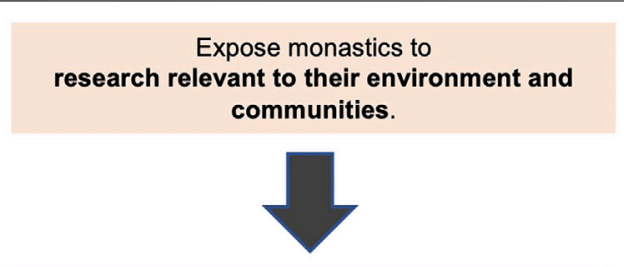

Overview experimental design components through guided set up of an experiment on what conditions radish seeds need to germinate.
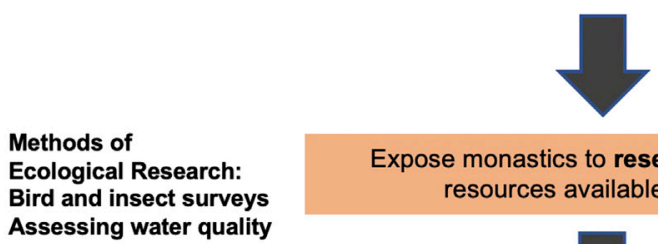

Expose monastics to research tools and resources available to them.

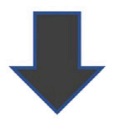

Have monastics brainstorm questions of interest to them, place related questions into

categories and identify group members with whom to work

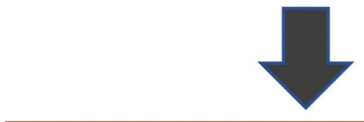

Help groups define project topics, hypotheses and research approach
Example at Intersection

of Mind, Body and

Neuroscience:

Impacts of Meditation

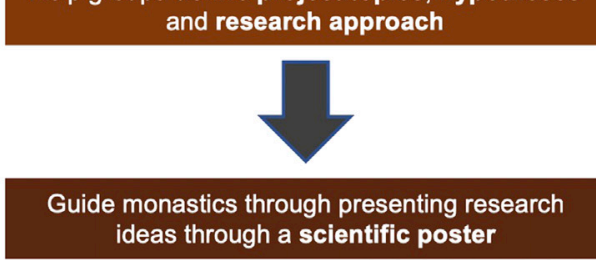

Methods of

Mind and Body Research: Self-Report surveys, Measuring pulse

FIGURE 1 | Overview of components of ETSI research training pilot workshop.

Following the core characteristics of active learning and CUREs, in the first days, we overviewed the scientific process through designing a group experiment and presented research that monastics and their communities would find relevant (Figure 1). We focused on research in two broad themes: 1) Ecology, Environment, and Public Health and 2) Mind and Body. We described an array of research methods used in these fields. For example, we collected local water samples and talked about methods to identify mosquito larvae, an important concern given the prevalence of mosquito-vectored diseases in India. We also demonstrated methods to collect data on heart rate variability and other health measures, some of which have been studied in relation to the meditation practices central to Tibetan Buddhism (Peng et al., 2004; Phongsuphap et al., 2008). The monastics were given time to propose questions that were of interest to them and confer with one another as they formed research teams. Each team, through guided instruction, generated a hypothesis, research design, and plan for collecting data. They created posters, much like those presented at scientific conferences, to communicate their research plans.
From this pilot, we learned many things. First, the pilot made it clear that the monastics have diverse interests that are shaped by their lived experiences. While we expected the monastics to gravitate towards research projects related to meditation, a practice central to Tibetan Buddhism, this expectation was narrow and naïve. One group of monastics, for example, developed a research proposal on how gardens could impact both the presence of pollinators and human happiness. Other proposals focused on health of the monastic community, highlighting concerns about weight gain and exposure to environmental toxins, a global concern. In other words, monastics demonstrated a wide range of research interests that were contextual and focused on both physical and mental health. Going forward, the Research Training Program will benefit from capitalizing on these interests. Second, the pilot emphasized what many instructors in the first phase of ETSI learned: the monastics bring a unique perspective that can shape our perceptions of the world and research going forward. We recognize that, although monastics may engage in research projects in similar ways as their ETSI mentors from the U.S., their motivation to pose questions in 


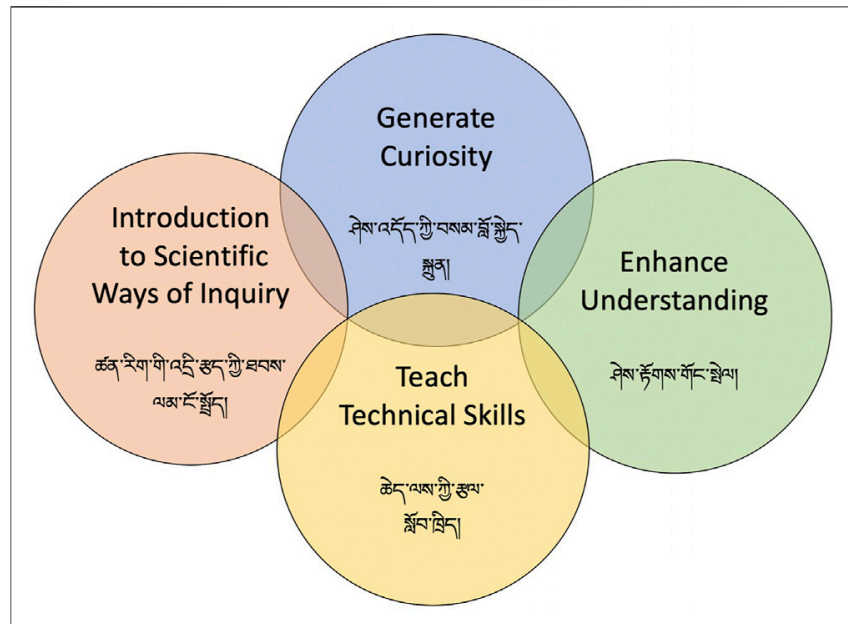

FIGURE 2 |Four learning objectives for the Emory-Tibet science initiative research training program.

certain ways is likely shaped by their own worldviews and epistemologies (Motokawa, 1989). Third, doing scientific research takes time, and the monastics, like traditional academics, have many demands on their time. Indeed, while we envisioned that the monastics would actually conduct these projects after the pilot workshop, their other obligations, our research and family obligations, and a lack of appropriate structures for us to support them from afar made this not feasible. Thus, any research training going forward must build a sustainable model for engaging monastics that accounts for these constraints.

\section{CONCEPTUAL FRAMEWORK FOR RESEARCH TRAINING PROGRAM}

We have four learning objectives for the Research Training Program (Figure 2). The first is to generate a sense of curiosity and excitement for research and the scientific process. This curiosity centers around an inquiry mindset (MacKenzie and Bathurst-Hunt, 2018), the concept that asking and answering questions are at the heart of research. The spirit of this inquiry mindset is nicely captured by Rachel Carson, who said "The aim of science is to discover and illuminate truth" (Lear, 1998). Thus, research is inspired by a systematic method of asking questions about the natural world, as is Buddhism. At its core, Buddhism is a set of practices and analytical methods for asking questions about mind and the fabric of reality (Dreyfus, 2003; Wallace, 2003). Although the methods may differ, the spirit of curiosity and inquiry are similar in science and Buddhism, which will be highlighted by the Research Training Program.

Our second objective is to introduce the monastics to scientific ways of inquiry and to help them become familiar with conducting research projects. There are three models for incorporating research into science education (Staub et al., 2016). The first is for instructors to design laboratory exercises that demonstrate phenomena or test hypotheses that have previously been tested. Numerous studies, however, have demonstrated that authentic research experiences, in which students conduct research to study questions for which the answer is not known, are more likely to increase students' interests in science and to bolster their identity as scientists (National Research Council, 2000; Gilardi and Lozza, 2009). Authentic research experiences can follow one of two inquiry approaches (Balgopal et al., 2017): directed (the instructor may come up with the experimental design) or guided (students develop their own experimental designs). In the second approach, instructors encourage students to define their own authentic research questions and to develop their own experiments, (open inquiry). The type of inquiry instruction that is, most appropriate for a particular group of students depends on the students' background knowledge and experience, as well as the instructors' ability to scaffold the research process. Below, we outline a 3 -year training model to help monastics transition from a more guided research training experience to a less guided experience.

Our third objective is to begin to teach the monastics technical skills needed for research inquiry. Given the confluence between Buddhism and neuroscience, we will prioritize training in methods of cognitive neuroscience (e.g., EEG). Starting in years two and three, we will complement training in cognitive neuroscience with training in other methods commonly used in biology.

Our fourth, and final objective, is to continuously enhance the monastics' understanding of science and research. The Dalai Lama calls ETSI a hundred-year project, recognizing that it may take a long time to generate fully independent science curriculums and research initiatives. This insight provides a unique opportunity to teach about the slow arc of research, and the fact that it can take generations for theories to be fully developed and tested.

\section{SPECIFICS OF RESEARCH TRAINING PROGRAM COURSE DESIGN}

The 3-year sustainability phase of the ETSI program will involve an educational program where monastics will participate in both disciplinary studies and research training.

\section{Year 1. Introduction to Scientific Ways of Inquiry and an Authentic Group Research Experience}

In the first year of the Research Training Program, monastics will be introduced to the concept of the inquiry mindset, and participate in discussions about the shared spirit of curiosity and investigation in science and Buddhism. The monastics will be introduced to the research mindset and scientific process while developing a scientific vernacular in Tibetan, given that most monastics enter the program with little or no prior knowledge of English. The instructors will work closely with the translation team to generate a vocabulary of research terms in Tibetan, and to translate course and research materials from English into Tibetan. 
There also will be live translation of lectures and workshops from English into Tibetan. The efforts of the translation team are truly historic, as there has never been, to the best of our knowledge, such an organized and systematic effort to translate scientific terms and concepts into another language.

Consistent with our commitment to experiential learning, a primary focus of year 1 will be for monastics to begin working on an authentic research project examining a question for which the answer is not known. In order to provide structure to the course, we will preselect this first research question and will guide the trainees through the process of designing and implementing a research project and testing hypotheses.

Our next objective for year 1 is to introduce the monastics to different methods for testing their hypotheses and conducting research, more generally. They will be introduced to experimental design and methods for collecting self-report (e.g., Qualtrics) and behavioral data, managing and tracking such data (e.g., Excel, Google docs), and scoring and processing data. We will also introduce monastics to methods used in cognitive neuroscience. We plan to build an electroencephalography (EEG) laboratory at the Drepung Loseling Meditation and Science Center and also purchase a number of mobile EEG systems, since these are frequently used to study human brain activity.

The COVID-19 pandemic and further reflection prompted us to envision a new model of how to make the training sustainable. To make this training and research development feasible, two of us (Nusslock, Gerardo) will work closely with Tibetan science educators who have advanced degrees in biology, physics, or neuroscience to develop the program. Together, we will establish a platform for continuous mentorship of the monastics. Over the year, we hope to foster several core characteristics of research, including collaboration and iteration.

\section{Year 2. Data Analysis and Small Group Project Development}

In the second year, research training will focus on data analysis and data presentation. We will use the data collected from the first-year research project for these training exercises. Monastics will learn how to generate descriptive data from their research projects and how to conduct introductory inferential statistics. Following analyses, we will introduce the monastics to strategies for visualizing and graphing their data, and giving scientific presentations.

Whereas the first-year research project will center on a preselected question, our goal for the second year is to help the monastics formulate their own research question and implement an experimental design. Depending on their interests, monastics may continue their training in cognitive neuroscience and learn intermediate EEG methods and be exposed to other methods. Alternatively, monastics will have the opportunity to switch their focus to other topic areas in biology or physics, depending on their interests. Monastics will work in small groups to carry out their second-year projects to benefit from each other's skills and to support one another. We will continue to support monastics in the second year as they implement their research projects.

\section{Year 3. Setting the Foundation for Continued Research}

In addition to continuing their training in data collection, analysis, visualization, and research methods, monastics will select a research topic in year three to specialize in. Our primary goal will be to help monastics set the foundation for continued research training beyond the sustainability phase. We anticipate that only a small group of monastics will want to move toward independent research, and our commitment will be to help these individuals pursue this goal and to become future leaders of research training for subsequent generations of monastics. For individuals interested in continuing their training in cognitive neuroscience, a select group will travel to the Affective and Clinical Neuroscience Laboratory at Northwestern University (Principal Investigator, $\mathrm{RN}$ ) in the United States for in-depth training. The hope is that this training will set a precedence for collaborative research projects between monastics and academic scientists. We will also help monastics interested in specializing in other research topics or methods make connections with academic scientists beyond the ETSI program.

After the sustainability phase, the science instruction will shift entirely to the Tibetan monastic community, so they can continue to provide both coursework and support for research endeavors for monastics who did not participate in earlier ETSI programs. Monks and nuns will continue learning about the philosophy of science, biology, neuroscience, and physics, but their instructors will be from within their monastic universities.

\section{CONCLUSION}

The goal of the Research Training Program is to help actualize the Dalai Lama's vision of integrating scientific knowledge and the wisdom of Indo-Tibetan traditions to serve the best interests of humanity. ETSI reflects the first major change in the Tibetan monastic curriculum in six centuries, and through the Research Training Program, monks and nuns are learning the conceptual foundation of science, and the experimental and technical skills to carry out research projects. As educators in ETSI, we are as much the students as the teachers. Buddhism has a remarkably sophisticated understanding of reality, and both analytic and experiential methods for investigating reality that have been refined over millennia (Motokawa, 1989; Jinpa, 2016). Furthermore, the highest spiritual ideal in Tibetan Buddhism is compassion. Our view is that academic science would benefit from being guided by the principle of compassion, and a commitment to enhance the welfare and well-being of all sentient beings. Academic scientists can learn a lot from Tibetan Buddhism and His Holiness, in the pursuit of this ideal. 


\section{AUTHOR CONTRIBUTIONS}

RN wrote the first draft of the manuscript and is Co-Director of the ETSI Research Training Program. NG wrote the section of the manuscript on the pilot program, was part of the pilot program team, and is Co-Director of the ETSI Research Training Program. JM was part of the pilot program team and edited the manuscript. JS was part of the pilot program team. MB was part of the pilot

\section{REFERENCES}

Auchincloss, L. C., Laursen, S. L., Branchaw, J. L., Eagan, K., Graham, M., Hanauer, D. I., et al. (2014). Assessment of Course-Based Undergraduate Research Experiences: A Meeting Report. CBE Life Sci. Educ. 13, 29-40. doi:10.1187/cbe.14-01-0004

Balgopal, M. M., Casper, A. M. A., Atadero, R. A., and Rambo-Hernandez, K. E. (2017). Responses to Different Types of Inquiry Prompts: College Students' Discourse, Performance, and Perceptions of Group Work in an Engineering Class. Int. J. Sci. Educ. 39, 1625-1647. doi:10.1080/09500693.2017.1346847

Balgopal, M. M., Gerardo, N. M., Topden, J., and Gyatso, K. (2021). Moving Past Postcolonial Hybrid Spaces: How Buddhist Monks Make Meaning of Biology. Sci. Educ. 105, 473-497. doi:10.1002/sce.21616

Dalai Lama, H. H. (2005). The Universe in a Single Atom: The Convergence of Science and Spirituality. New York: Morgan Road Books.

Davidson, R. J., and Lutz, A. (2008). Buddha's Brain: Neuroplasticity and Meditation [in the Spotlight]. IEEE Signal. Process. Mag. 25, 176-174. doi:10.1109/msp.2008.4431873

Dreyfus, G. (2003). The Sound of Two Hands Clapping: The Education of a Tibetan Buddhist Monk. Berkeley, CA: University of California Press.

Eisen, A., and Konchok, Y. (2017). The Enlightened Gene: Biology, Buddhism, and the Convergence that Explains the World. Lebanon, NH: University Press of New England.

Furtak, E. M., Seidel, T., Iverson, H., and Briggs, D. C. (2012). Experimental and Quasi-Experimental Studies of Inquiry-Based Science Teaching. Rev. Educ. Res. 82, 300-329. doi:10.3102/0034654312457206

Gilardi, S., and Lozza, E. (2009). Inquiry-Based Learning and Undergraduates' Professional Identity Development: Assessment of a Field Research-Based Course. Innov. High Educ. 34, 245-256. doi:10.1007/s10755-009-9109-0

Jinpa, T. (2010). Buddhism and Science: How Far Can the Dialogue Proceed? Zygon 45, 871-882. doi:10.1111/j.1467-9744.2010.01138.x

Jinpa, T. (2016). A Fearless Heart: How the Courage to Be Compassionate Can Transform Our Lives. New York: Avery Penguin.

Labouta, H. I., Kenny, N. A., Li, R., Anikovskiy, M., Reid, L., and Cramb, D. T. (2018). Learning Science by Doing Science: An Authentic Science ProcessLearning Model in Postsecondary Education. Int. J. Sci. Educ. 40, 1476-1492. doi:10.1080/09500693.2018.1484966

Ladyman, J. (2002). Understanding Philosophy of Science: Introduction. New York: Routledge.

L. J. Lear (Editor) (1998). Lost Woods: The Discovered Writing of Rachel Carson. Boston: Beacon Press.

MacKenzie, T., and Bathurst-Hunt, R. (2018). Inquiry Mindset: Nurturing the Dreams, Wonders, \& Curiosities of Our Youngest Learners. Irvine, CA: EdTechTeam Press.

Marshall, J. C., Smart, J. B., and Alston, D. M. (2017). Inquiry-based Instruction: A Possible Solution to Improving Student Learning of Both Science Concepts and Scientific Practices. Int. J. Sci. Math. Educ. 15, 777-796. doi:10.1007/s10763016-9718-x program research team and made substantial edits to the manuscript.

\section{FUNDING}

The publication of this paper will be funded by discretionary funds to RN (corresponding author).

Motokawa, T. (1989). Sushi Science and Hamburger Science. Perspect. Biol. Med. 32, 489-504. doi:10.1353/pbm.1989.0023

National Research Council (2000). How People Learn: Brain, Mind, Experience, and School. Expanded Edition. Washington, D.C.: The National Academies Press.

National Research Council (2003). BIO 2010Transforming Undergraduate Education for Future Research Biologists. Washington, D.C.: National Academy Press.

National Research Council (2012). Discipline-based Education Research: Understanding and Improving Learning in Undergraduate Science and Engineering. Editors S. R. Singer, N. R. Nielsen, and H. A. Schweingruber (Washington, D.C.: The National Academies Press).

Peng, C.-K., Henry, I. C., Mietus, J. E., Hausdorff, J. M., Khalsa, G., Benson, H., et al. (2004). Heart Rate Dynamics during Three Forms of Meditation. Int. J. Cardiol. 95 (1), 19-27. doi:10.1016/j.ijcard.2003.02.006

Phongsuphap, S., Pongsupap, Y., Chandanamattha, P., and Lursinsap, C. (2008). Changes in Heart Rate Variability during Concentration Meditation. Int. J. Cardiol. 130 (3), 481-484. doi:10.1016/j.ijcard.2007.06.103

Popper, K. R. (1959). The Logic of Scientific Discovery. London: Hutchinson of London.

Russell, B. (2001). The Problems of Philosophy. Oxford: Oxford University Press.

Sonam, T. (2019). "Incubating Western Science Education in Tibetan Buddhist Monasteries in India," in Science Education in India (Singapore: Springer), 27-45. doi:10.1007/978-981-13-9593-2_2

Staub, N. L., Blumer, L. S., Beck, C. W., Delesalle, V. A., Griffin, G. D., Merritt, R. B., et al. (2016). Course-based Science Research Promotes Learning in Diverse Students at Diverse Institutions. Counc. Undergr. Res. Q. 37, 36-46. doi:10.18833/curq/37/2/11

Wallace, B. A. (2003). Buddhism and Science: Breaking New Ground. New York, NY: Columbia University Press.

Conflict of Interest: The authors declare that the research was conducted in the absence of any commercial or financial relationships that could be construed as a potential conflict of interest.

Publisher's Note: All claims expressed in this article are solely those of the authors and do not necessarily represent those of their affiliated organizations, or those of the publisher, the editors and the reviewers. Any product that may be evaluated in this article, or claim that may be made by its manufacturer, is not guaranteed or endorsed by the publisher.

Copyright (c) 2022 Nusslock, Gerardo, Mascaro, Shreckengost and Balgopal. This is an open-access article distributed under the terms of the Creative Commons Attribution License (CC BY). The use, distribution or reproduction in other forums is permitted, provided the original author(s) and the copyright owner(s) are credited and that the original publication in this journal is cited, in accordance with accepted academic practice. No use, distribution or reproduction is permitted which does not comply with these terms. 